\title{
CONTENTS
}

INTESTINAL OBstruction From Gall-stone. "Gall-Stone Il.eUs." By G. Grey Turner, M.S., F.R.C.S.(Illustrated) . • . . . . .

A Symposium on Indigestion. III. The Medical AsPECT.

By J. Campbell McClure, M.D.

Minor Degrees of Spinal Curvature.

By G. Perkins, M.C., M.Ch., F.R.C.S .
English Women in Life aNd LetTers.

By M. Phillips and W. S. Tomkinson .

Edtorial Notes:-Post-Graduate Work in Provincial Centres.-Official Intimations

Feluowship of Medicine and Post-Graduate Medical Association :-Officers, 1927 . $\quad$ - 5 Special Courses

.

\section{INTESTINAL OBSTRUCTION FROM GALL-STONE.* "GALL-STONE ILEUS."}

\section{A PITfall FOR THE PRACTITIONER.}

BY

G. GR E Y T UR N ER, M.S., F.R.C.S., NEWCASTLE-UPON-TYNE.

I AM well aware of the rarity of this condition, but rarities often become comparatively common when they are better understood, and it is highly probable that many cases set down as gastritis, or recurring colic, or vomiting of undetermined origin, or intestinal indigestion or other conditions that occur to one may really be examples of overlooked obstruction from impacted gall-stones. In the early days of the Great War I was very much impressed by a fine old colonel whom it was my privilege to look after in what unfortunately proved a fatal illness. He was one of those who came under the category of " dug out," but as with many others so designated, I learned to respect and admire him. This old soldier told me that since his retirement he had made a practice of rising at six o'clock every morning, just in case he might be called up again for active service, and in order that he would be quite ready to take up his duties when the summons came! That is a good attitude for us all, for it is only by being ready to recognise and to deal with unusual conditions that we can feel ourselves equipped for the work we have been called upon to do.

Now I suggest to you that this condition is perhaps not so rare, and I am forcibly reminded of this by the circumstances of a recent casethat of an old doctor who had laboured long and honourably until in his 77th year he became affected with a very trying skin condition. When

* A lecture delivered to post-graduates under the auspices of the Fellowship of Medicine. he seemed to be recovering he was suddenly seized with the most violent abdominal pain and vomiting, and appeared to be in extremis. He told his housekeeper that he was sure a stone had passed into the bowel and had become impacted, and insisted that $I$ should be summoned. In a few hours he had apparently recovered, but vomiting went on at intervals, and was often intestinal in character, and whenever he appeared to be nearly well the trouble returned, until he finally died. I shall always regret that I did not accept his diagnosis and open the abdomen, and that a postmortem examination was not made, for I feel quite certain that he was right, and that a gallstone was attempting to traverse the intestine.

Before dealing with the features of gall-stone ileus, I want to say something about intestinal obstruction in general, because I recognise that I am addressing post-graduates whose didactic teaching was probably received a good many years ago, when the picture of intestinal obstruction was painted from a later stage than we are accustomed to recognise to-day. The old picture was of a patient who had passed neither flatus nor fæces for days, and by whose bedside was a bowl filled with horribly smelling intestinal contents which was constantly being regurgitated. The abdomen was greatly distended, and too often the patient had sunken eyes, cold clammy skin, subnormal temperature, and a feeble-running pulse.

This really represents a condition in which symptoms from the absorption of toxins have been added to those of purely mechanical obstruction, and is a state preceding death. Quite often, when asked to see cases, I am confronted by the statement that the vomit is not fæcal, the suggestion being that the case cannot be one of obstruction because of this omission, or that if obstruction exists, it cannot at all events be of a serious nature. In this connexion let me quote some very wise words that were written long ago by my friend, Mr. Sampson Handley, words which one recognises as very true, and which ought to be remembered as a help to the understanding of this subject. 
He writes : “ Fæcal vomiting is not to be regarded as a symptom of intestinal obstruction, but as a herald of approaching death."

The main features, then, of intestinal obstruction as we are accustomed to see it at the present time, and at a stage at which it ought to be recognised, are as follows :-

\section{Symptoms.}

An attack of abdominal pain.

Intermittent colic.

Vomiting.

Inability to secure the passage of flatus.

\section{Physical Signs}

(irrespective of the Causative Factor).

Evidence of exalted peristalsis-observation of contracting intestinal coils and increased peristaltic sounds as heard with the stethoscope.

Gradually increasing abdominal distention.

Character of the vomit.

It is also well to remember the following points about cases of suspected obstruction :-

The pulse may be unaffected.

The temperature is no guide.

There may be no initial collapse and but little general disturbance.

The vomit may be slight in amount and not necessarily intestinal.

The bowels may move.

There may be no obvious distension.

In such cases, the test of obstruction is the inability to secure the passage of flatus, the continued and altering vomiting, and the steadily increasing distension of the abdomen.

\section{Features of Gall-stone Obstruction.}

With these preliminary considerations we may now pass to the features peculiar to gall-stone obstruction itself. This is a condition which occurs in females at least five times more frequently than in males, and, in fact, in my series there was only one male among eight cases. It is also a disease of elderly people, and I have never seen an example in a person less than 50 years of age, and, indeed, in my small series the average age was no less than 68 , but in a very large number of cases mentioned by Barnard the average age was just over 60 . The onset, though usually sudden and severe, may be more gradual, and is not characteristic. Let me remind you that the main features are as follows:-

Early and copious vomiting which soon becomes intestinal.

Incomplete obstruction in the early stages.

Marked intermission of symptoms.

Rapid maturation of recurrent symptoms.

Absence of distension and other physical signs.

These points can best be illustrated by the records of cases.

The first patient I wish to refer to was a hale old lady of 79 whom I saw with her medical attendant in December, 1924 (Reg. No. 16,352, Case 8 $\dagger$ ). She had always been looked upon as a healthy woman, though rather subject to bronchitis. While having her family (there had been four children) she had suffered from severe bilious attacks

+ The cases are numbered according to the table following, and not in the sequence in which they are quoted. with headaches, vomiting and general seediness, but without abdominal pain. The bowels moved regularl each morning. On a Thursday morning this old ladje felt quite well, and went out shopping as was her custom 3 While in town she felt very tired, and that afternoon could not preside at the tea-table. She went to bed early anc fell asleep, but was awakened with griping pain and wind: though it was not very severe. She got up on Fridax morning and had the bowels moved as usual, but did not feel very well, and about mid-day vomited. That nigh? the patient again went to bed early, but was disturbed witlo pain and further vomiting. The bowels moved slightly during the night. On Saturday morning her medica attendant was summoned for the first time. When seer the patient did not appear very ill, there were no physica» signs, and both pulse and temperature were normal. The doctor was a little anxious, however, because the vomi was described as coffee ground, but unfortunately it had been thrown out and could not be inspected.

The patient was given a Bismuth mixture and a powdee of Calomel and Hyd. c. Creta, but this was vomited, ang between 11 and 11.30 vomiting was rather frequent About 3.30 that afternoon she was again visited, and. though she did not appear much worse, the specimen of vomit was recognised as being intestinal in nature, and it was arranged that she should be seen by a surgeonos which I did that evening about 5.30. I found the oldr lady lying comfortably in bed and looking her usual, she would scarcely complain of pain, and only admitted veryslight infrequent colic. The pulse was about 70 and the tongue quite clean, while the abdomen was flat, and ther® was nothing abnormal to be felt and no visible or audible peristalsis. The hernial sites and the rectum were carea fully examined, but with a negative result. The vomid which I was able to inspect was undoubtedly intestinal in nature. The symptoms therefore suggested obstruction and the most likely explanation appeared to be either the impaction of a gall-stone or an obturator hernia. In view of the improvement in her condition an enema waso ordered, and if that was without result it was to be followeds by Calomel, $\frac{1}{2} \mathrm{gr}$. each half-hour until she had taker 4 grains in all.

I must say that I left the house with the expectation that $I$ would be summoned again in a few hours, but, a? a matter of fact, I. heard nothing until 10.15 on Sunday $\vec{F}$ morning, when I was informed that the patient was worse? that there had been very little if any result from the enema, and that she had suffered much more pain and had vomited frequently. About noon $I$ found the patient? in pain, which was quite bad at times. There was mucho tendency to vomit, and what was ejected had the same 3 intestinal odour but was thinner than before. The patient. now looked in some distress, and the pulse was over 100 .

The diagnosis of obstruction being confirmed, a smalk. dose of morphia was given and arrangements made foro an operation in her own house, and this was performed at 2.30 on that Sunday afternoon. Local anæsthesiao was used, the abdominal wall being thoroughly infiltrated? and a sub-umbilical median incision employed. It had to be about $6^{\prime \prime}$ long on account of the great depth of subcutaneous fat; but the actual opening in the peritoneum was not more than $3^{\prime \prime}$ in extent. On opening the cavityos a small amount of free fluid escaped, and collapsed small intestine was noticed towards the lower part of the abdomen, while that in the upper part was distended. AN coil of the latter was drawn into the wound, and a largeo impacted gall-stone was immediately found. The gut was tightly stretched over the calculus, but there was no든 unusual contraction of the bowel above the obstruction, $\mathbb{D}$ and no sign of gross change in the bowel wall at the point? of impaction, these points suggesting that the stone had not lain for long in the same position.

An incision was made over the stone in the long axis of the bowel, and the calculus easily squeezed out, $\stackrel{\oplus}{\oplus}$ together with some mucus; the intestinal wall looked normal. The incision of the gut was closed in the trans-o verse axis of the bowel. No other calculus was felt in the neighbouring intestine, but it was not possible to reach and examine the gall-bladder. The abdominal wall waso 
closed, the patient having stood the operation extremely well. She vomited once or twice afterwards, but on the whole the old lady's recovery was very satisfactory although there was a little infection in the wound about the tenth day.

The calculus (Fig. 1) was roughly rounded, suggesting that a faceted stone had been added to. It measured

Fig. 1.

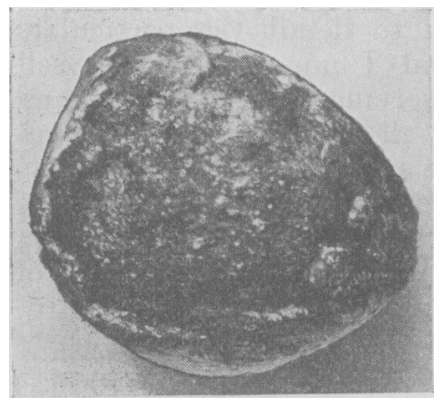

Gall-stone removed from the small intestine, Case 8. (This and the other calculi illustrated are actual size.) $1 \frac{1}{2}=1 \frac{1}{4}$, and weighed 205 grs., and was one of the largest I have ever removed in a case of gall-stone ileus.

In arriving at a diagnosis in this case, the previous history was no guide, for here was a bright intelligent old lady surrounded by her daughters who had always lived with her, and who were perfectly sure that there had never been any previous abdominal pain, nor any uneasiness or discomfort referred to the region of the gall-bladder, nor any attack of jaundice. Then, again, the symptoms in the early stages were so slight that it was not deemed necessary to call in the doctor, and even when seen there was little on which to make a diagnosis. During the intermissions the patient seemed so comfortable that spontaneous recovery was confidently expected, but the Calomel made the symptoms definite, and in that way proved valuable.

The next case is an admirable illustration of the intermissions that may occur in the symptoms. In fact, the period of intermission might well be styled the "lethal interval," so deceptive may it prove.

The patient was Miss A. D., aged 56 (Reg. No. 8,456 and 8,457 , Case 4) and the first intimation I received about the case was a message from her doctor on a Monday morning in August saying that he wanted to bring an abdominal case to consult me that afternoon. Being a very busy day I said that I should prefer to see the patient on Wednesday, but that if it was urgent she had better come in the evening at 7 o'clock. On arriving at my private hospital about 7.30 the same evening $I$ found that the patient and her doctor had motored in from the country - a distance of 30 miles.

The doctor told me that for 10 years or more his patient had suffered from stomach trouble, said to be indigestion. The pain always came on after food, and sometimes continued until relieved by morphia. The upper abdomen was sore to the touch after the attacks. She had a very bad seizure nine months previously and was six weeks in bed. Five months ago there was a further attack, after which she walked in a stooping posture, and the bowels would not act without medicine. About three years ago the patient's half-brother was operated upon for gallstones, and the patient was looked upon as suffering in the same way, but she had never been jaundiced. The present attack began two weeks previously, and seemed to be passing off as usual until to-day, when the vomiting became more copious then ever before, and was of quite a different character, suggesting an intestinal origin. This caused alarm and led the doctor to decide to bring the case into Newcastle. The patient was an elderly woman, whom I found sitting in the waiting-room fully dressed and looking in what $I$ judged to be her normal state of health. She protested that she was quite better, and rather questioned the necessity of being hustled into town. I had her taken upstairs and undressed, but could make nothing out on examination. In view of the fact that the doctor had been so much alarmed about the condition of the patient that he had taken the trouble to bring her into Newcastle that Monday night, and his statement as to the nature of the vomit, I decided that it would be wiser for her to remain under observation, though I could not imagine at that time that there was anything serious amiss. The patient was therefore put to bed and given an enema with some result. She had a very good night, but in the early hours of the morning vomited a large quantity of distinctly intestinal contents. A diagnosis of intestinal obstruction from gall-stones was then made, and the same afternoon an operation was carried out.

The stomach was first washed out, and under general anæsthesia an incision was made below the umbilicus. Almost at once a distended coil of intestine was found containing a gall-stone impacted in its lumen, though not very firmly and without any evidence that it had lain in that position for any length of time. A few inches higher up the intestine there was another and smaller calculus almost loose in the bowel. The gut above the obstruction was moderately distended, and that below somewhat collapsed, but there was not the great difference in the two portions of the bowel that is usually seen in cases of absolute obstruction. The calculi were removed by an incision into the bowel, and it was observed that they were faceted, suggesting a further calculus which was missing. The intestine was examined for two or three feet above the site of obstruction, but without discovering any sign of the remaining stone, and it was

FIG. 2.

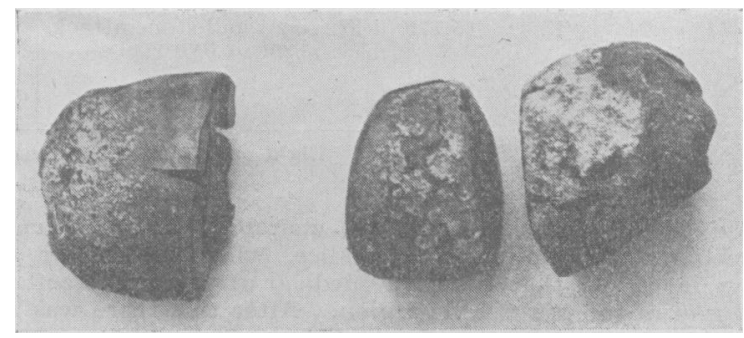

Gall-stones removed from the small intestine in Case 4. The two on the right were found at the first operation, that on the left 12 days later.

concluded that it had probably passed in the attack about Christmas time. The abdomen was therefore closed. The patient stood the operation perfectly well.

For a day or two she complained of abdominal pain, but this she assured us was her old pain, and in no way connected with the trouble which brought her to Newcastle. After two or three days it completely disappeared; the bowels were moved; she took food well, and appeared to be quite all right. About the tenth day srmptoms of a further obstruction developed, and as this did not clear up by palliative means, I decided to re-open the abdomen. and this I did on the twelfth day following the original operation. There was a considerable amount of fluid in the abdomen and the intestine at about the point which had previously been opened was adherent to the back of the incision by a large strong band. At this point there was also some torsion, but it was in the middle of a distended coil of intestine, and had evidently nothing to do with the recurrent obstruction. On making further search a large gall-stone was found impacted in the bowel, and was removed. This was the fellow to the calculi previously removed. The hand was introduced and a 
large mass of adherent omentum felt in the neighbourhood of the gall-bladder, but this was not disturbed.

The patient this time made an uninterrupted recovery, and was completely relieved not only of her obstructive symptoms, but of what she called her "old pain" that had troubled her for so many years.

Of the two calculi removed at the first operation, the largest measured $11^{\prime \prime} \times 1^{\prime \prime}$, and together they rveighed 203 grs., while the one removed at the second operation weighed 128 grs. (Fig. 2). Ten years later this patient reported herself in good health, without any recurrence of her old symptoms.

The next case illustrates the great importance of the remission of the symptoms and of the inspection of the vomited matter.

The patient, A. S. (Reg. No. 11,101, Case 5), was a widow aged 65 , whom I was asked to see in 1918 . I was told that she had frequently suffered from attacks of pain in the upper abdomen. These were at first looked upon as due to gastritis, as there was vomiting and tenderness over the stomach. After baing troubled in this way for sone
My notes are brief and incomplete, reflecting the pre occupations of that anxious time, but I have the cleares recollection of the main factors-the anxiety of Dr. Smitl? as to the condition of his patient, the misleading lethaK interval in which I first saw the case, the absence of th\& valuable evidence which the vomit would have supplied, and the lack of guidance from any other physical signs. I take: entire responsibility for the result, and am glad to have्ष this opportunity of expressing my appreciation of Dr. Smith's acumen and my indebtedness to him for his fore bearance in spite of $\mathrm{my}$ bungling.

It would weary you to detail the particular: of the other cases, and I must content myself with an epitome, reserving the notes for arw appendix. They have all shown similar features and have conveyed the same lessons. The follow:ing table gives very briefly the features of all the्w cases which I have personally had under my ows care during the period of 17 years to the end of June, 1925 :-

\begin{tabular}{|c|c|c|c|c|c|c|c|c|}
\hline No. & Age. & Sex. & $\begin{array}{l}\text { Reg. } \\
\text { number. }\end{array}$ & Previous symptoms. & $\begin{array}{l}\text { Site of } \\
\text { impaction. }\end{array}$ & Operation. & Result. & After-history. \\
\hline 1 & 72 & F. & 1,513 & $\begin{array}{l}\text { Gall-stone attack two } \\
\text { years previously. }\end{array}$ & $\begin{array}{c}\text { Simall } \\
\text { intestine. }\end{array}$ & Removal. & ( $\subseteq$ & $\begin{array}{l}\text { Died } 12 \text { years later. } \\
\text { No recurrence. }\end{array}$ \\
\hline$\ddot{z}$ & 70 & F'. & 1,744 & (xall-stomes some months. & , & Finterostomy & D. & - \\
\hline 3 & 63 & M. & 5,280 & None. & , & Removal. & C. & - \\
\hline 4 & 56 & F. & $\begin{array}{l}8,456 \\
\text { and } \\
8,457\end{array}$ & Indigestion ten years. & . & , & $\therefore$ & $\begin{array}{l}\text { Further stone removed } \\
12 \text { days afterwards. } \\
\text { Well ten years later. }\end{array}$ \\
\hline j & (j5 & F. & 11,101 & Gall-stones six months. & ,. & , & D. & - \\
\hline (; & 70 & $\mathbf{F}$ & 11,790 & $\begin{array}{l}\text { Gall-stones five years and } \\
\text { three years previously. }\end{array}$ & Pelvic colon. & , & C. & $\begin{array}{c}\text { No recurrence five years } \\
\text { later. }\end{array}$ \\
\hline 7 & $7 \pm$ & F. & 15,779 & $\begin{array}{l}\text { Frequent gall-stone attacks } \\
\text { four or five years. }\end{array}$ & $\begin{array}{c}\text { Small } \\
\text { intestine. }\end{array}$ & , & C. & $\begin{array}{c}\text { No recurrence } 18 \text { months } \\
\text { later. }\end{array}$ \\
\hline 8 & 79 & F. & 16,352 & None. & , & , & C. & Recent. Well to date. \\
\hline
\end{tabular}

Eight cases with nine operations and two deaths.

months, the attacks altered in character, and she had severe colic, followed by jaundice, which lasted for a few days. At that time her medical attendant detected a lump about the pyloric region. After this there was a lull for about a month, when colicky pains with vomiting recurred. One evening Dr. James Smith, of Newcastle, asked me to see this patient, as he thought she was suffering from intestinal obstruction, and that an operation would be necessary.

At the time of my visit the patient was apparently quite well again, there were no physical signs, and the vomited matter had unfortunately been thrown out contrary to the doctor's orders. In spite of the history and of the insistence of Dr. Smith, I was misled, delay was countenanced, and further remedies proposed. Seven days later the condition had recurred; in fact, the patient had never been quite relieved, and it was now only too obvious that she was suffering from a mechanical obstruction to which toxamia was being superadded.

An operation was carried out, and a mass found at the pylorus with great dilatation of the stomach. Again I was misled, and gastro-enterostomy was contemplated, but the small intestine was so distended and sodden that at last I found myself on the track, and a search of the upper intestine discovered a large gall-stone impacted in its lumen. This was removed, but the operation showed that the patient was more affected by toxæmia than had been supposed, and death occurred suddenly a few hours later. The mass at the pylorus was found to be the thickened and inflamed gall-bladder, which was adherent to the stomach and intestine.
In addition, it was my privilege to see quite ap. number of other cases under the care of $\mathrm{my}$ col leagues during the seven years that I acted as . Surgical Registrar at the Newcastle Infirmary: and I am glad to once again have the opportunit $\%$. of drawing attention to the great advantages whicl such a post confers on anyone who will use it及 opportunities as he should. William Hunter once said that if he were to make a man truly great in his profession, he would put him in a large hospita? where he might attend the sick and dissect the dead, and that is precisely what a surgical registraP is enabled to do. The mere making of records is of immense value if it is properly done. Onङ admits the labour involved, but the storing up of information in this way is of very great value and the main points are emphasised better b recording than in any other way. Personally, P? very much regret the change in the system byo which the surgical post mortems are now handed, on to the Pathological Department, for I am sure that it is very much better that patients should be followed from the wards by those who hav known them in the wards, and that the investigation which probably commences in the receiving rocm 
should not be given up until the patient leaves the hospital, irrespective of the exit employed.

The main points, then, brought out by a consideration of these cases is the curious periods of relief and the incomplete obstruction in the earlier stages of the illness. Now what is the explanation?
Fig. 3.

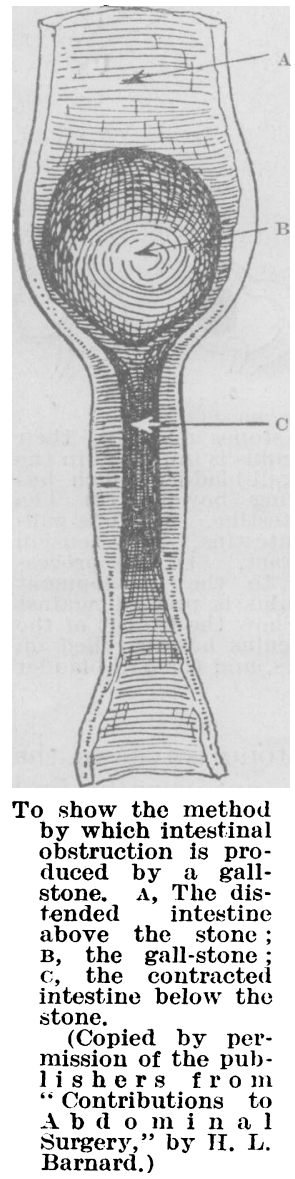

Fig. 5.

Two gall-stones composed mostly of pigment. The larger one, half inches in length, was and its fellow from the ileun and its fellow from the ileun where it had become impacted. University of Durham College of Medicine.)

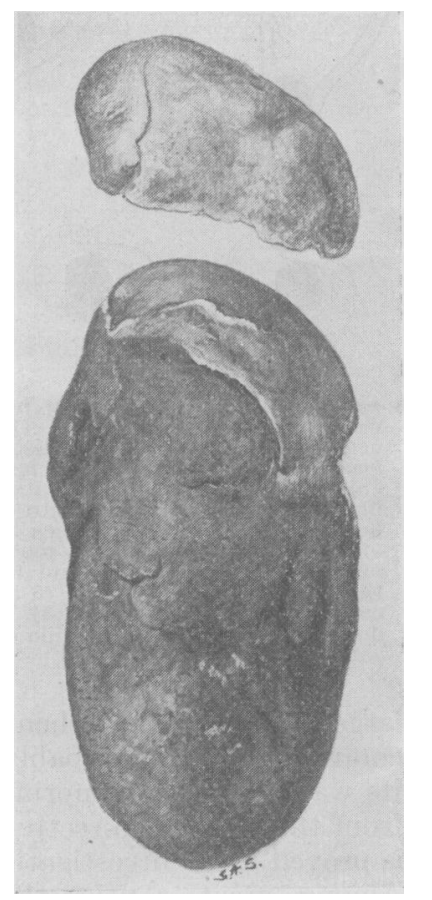
which measured two and a

This is best understood by referring to Fig. 3, which shows how the obstruction is purely mechanical, and is brought about by the attempt on the part of the stone to travel along the intestine. But so large a foreign body is resented, and a spasm is set up by way of protest. With any but the very largest stones it is probably not a matter of great difficulty for them to travel for a considerable distance until they arrive at a point in the intestine at which there is a very marked disproportion between the size of the stone and the lumen of the bowel. The intestine acts by contracting and relaxing on its contents, and so it must behave in the presence of a stone which is attempting to traverse the bowel. Not being able to easily propel the stone, the gut is thrown into violent spasm, and this means that the bowel beyond the stone is unduly contracted while the bowel at the site of the stone firmly grasps the latter, and naturally the obstruction becomes more or less absolute. The bowel above the stone is also contracted, but never to the degree in which the contraction affects the bowel beyond. When the bowel is in this contracted stage the patient has pain, there is violent antiperistalsis and vomiting, but when the spasm in the intestine passes off the stone gradually and quietly meanders along the intestine for some distance until another spasm is set up, and the symptoms recur with their original violence. This may go on for quite a long time, the stone traversing a considerable length of intestine, and it is well known that this process may suffice to propel the stone through the ileocæcal valve into the large intestine, from which it may be easily passed. In the old days there were several cases recorded in which the stones had been voided spontaneously, the obstruction being thus cured without the interference of the surgeon.

But it is much more usual for the stone finally to reach a point at which it becomes firmly impacted, and at which further progress is barred. The intestine about the stone is then found in a state of permanent spasm, the bowel wall is thinned and often ulcerated, and above the point it is distended, infected, and sometimes ulcerated. There is often peritonitis originating from an infection which has traversed the bowel wall just

\section{FIs: 4.}

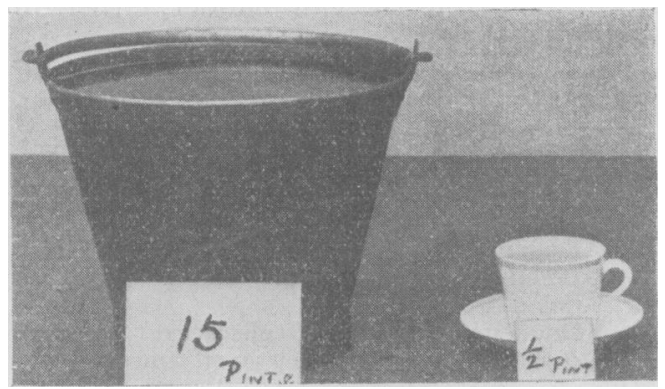

Shows graphically the daily quantity of gastro-iutestinal secretion. The breakfast cup contains half-a-pint in contrast with the bucket containing 15 pints which is the average amount secreted in 2.4 hours.

above the site of the impacted stone, or there may be perforation of an ulcer.

All these points are amply illustrated by reference to cases, and I have at various times found examples of all the conditions just mentioned.

Another feature of gall-stone ileus is the extraordinary amount of the vomiting, and it has frequently been remarked that it is impossible to comprehend where all the vomited matter can come from. It is interesting to pause for a moment just to realise the enormous amount of secretion that normally finds its way into the stomach and intestine. A computation made by reference to numerous authoritative works and the help of 
my physiological friends recently kindly revised by Prof. D. Burns, enables me to make the statement that in the 24 hours no less an amount than about 15 pints of one secretion and another is poured into the gastro-intestinal tract (Fig. 4). 'This is three or four times the volume of the urine and twice the volume of the blood. The computation takes no note either of the amount of fluid that may be taken in by the mouth nor of the increased amount of secretion that may follow on the one hand the irritation in the intestine, or on the other the irritation brought about by the remedies that may be used for the attempted cure of the condition.

Then another difficulty is to explain the practically normal condition of the patient between the attacks. We must recognise that there is no strangulation and no interference with the blood supply of the bowel, and that it is only after a stone has become permanently impacted that toxic absorption is likely to take place, so that in the earlier stages there is not enough interference with the normal working of the gastro-intestinal tract to allow of toxic symptoms arising.

The absence of previous symptoms of gall-stones is often a remarkable feature. When confronted with these cases people invariably say what a curious thing that the patient has never had a history of jaundice! As a matter of fact, gallstones which are sufficiently large to produce intestinal obstruction do not often traverse the common duct, but find their way into the intestine by ulceration from the gall-bladder, either directly into the duodenum, or into the large bowel. Many years ago (1890) Courvoisier went carefully into this matter, and from post-mortem investigation of 36 cases he found that the common routes were as follows :-

Through a gall-bladder-

Duodenal fistula 25 times.

Ileum fistula once.

Colon fistula once.

Duodenal and colon fistula twice.

Through the common bile-duct seven times.

In addition to those mentioned in his table, I have seen the communication directly between the gallbladder and the stomach, and cases are on record in which gall-stones have actually been vomited. In the College of Medicine Museum in Newcastle there is a specimen (Fig. 5) showing two gallstones, composed mostly of pigment. The larger stone, which is dark green in colour, and measures two inches and a half in length, was removed, at operation, from the stomach. The smaller one, which is brown and possesses a facet which fits the end of the larger stone, was found impacted at the lower end of the ileum, where it was the cause of intestinal obstruction. A fistula between the gall-bladder and the duodenum was demonstrated. These calculi were removed by my colleague, Mr. T. A. Hindmarsh, from a woman of 53 on whom he operated for obstructive symptoms. The patient made a satisfactory recovery, and was in good health a year later. There mas be an opening into all three neighbouring viscers and not uncommonly into both the small and the

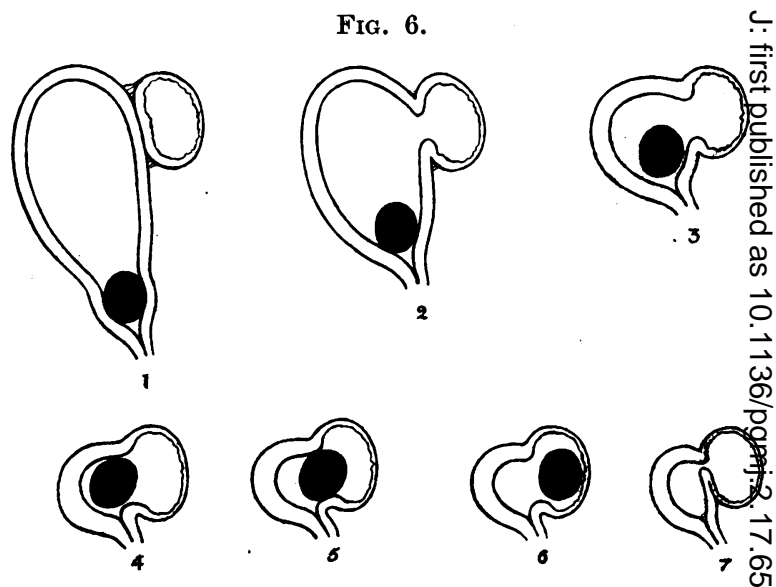

A series of diagrams showing how gall-stones may find theid way into the hollow viscera. (1) A calculus is impacted in the neck of an inflamed and distended gall-bladder which has. become adherent to the neighbouring bowel. (2) The gall-bladder has ulcerated into the intestine. (3) The gall bladder drains freely into the intestine, and tensiog being relieved it commences to contract. (4) The process of contraction which is partly due to the developments of scar tissue continues and the calculus is pressed against the opening in the bowel. (5 and 6) Show the transit of the calculus into the bowel. (7) The calculus has travelled on down the intestine, the fistula contracts, and the gall-bladdefo continues to shrivel.

large bowel. Even when the stone traverses the common duct it probably does not usually fin its way through the normal opening, but ulcerate from the ampulla directly into the bowel, and this is proved by an investigation of museum specimens? Among great rarities there are cases where th $\overrightarrow{\overrightarrow{\widehat{E}}}$ gall-bladder has burst into the urinary bladder, or even the uterus.

A knowledge of pathology, therefore, does not lead one to expect a history of jaundice in man of the cases, but it might be supposed that there. would always be a history of a definite and perhaps severe gall-stone illness leading up to the passage of the stone into the bowel. As a matter of experience this is not by any means always so and in my own series of eight cases such $\dot{a}$ histor $\ddot{p}$ was entirely absent in two and indefinite in third. Experiences of this sort made me pay. particular attention to this matter, and I soois found that many patients with distended gall bladders from obstruction of its neck or cystif duct have but few symptoms. In 1921 I operated on a female patient 44 years of age, who gave $\stackrel{\circ}{c}$ history that she had suffered from indigestion fof two months, with an attack of discomfort and soreness over the upper abdomen four days before she came under my observation. The gall-bladder was distended and reached nearly to the umbilicus yet the patient stated that " she could hardly sa! there had ever been pain." On opening th@ abdomen $I$ found an inflamed gall-bladder full of infected mucus, the result of the impaction of $a$ large stone in its neck. 
More than once I have seen similar cases where the patient would not submit to operation. The swollen gall-bladder has disappeared, sometimes suddenly, and all symptoms have ceased. In most of such cases the gall-bladder leaks into a hollow viscus, and the stone or stones may be gradually forced into the bowel by a slow process of ulceration, as shown in the illustration (Fig. 6). As soon as the tension in the gall-bladder is relieved, the symptoms disappear, and the process of the gradual extrusion of the stone into the bowel is unattended with symptoms. When the gallbladder and neighbouring parts are examined in these cases, the viscus is found to be small, thickwalled, and shrivelled, and the cystic duct commonly obliterated.

The opening which first forms is not large enough to allow a stone of such size as would cause obstruction to enter the intestine, but after a time the gall-bladder contracts down on its contents and causes the stone to be pressed against the sinus which is gradually enlarged by ulceration until it is big enough to let the calculus through. This is very well shown in the following illustration of a specimen from the College of Medicine Museum in Newcastle (Fig. 7). In this specimen the two stones had evidently lain together with the broad facets in apposition, and the fistula is just of the exact size of the stone in the intestine.

For some little time after the passage of the stone the fistula probably only slowly contracts, because in one or two instances it has been found possible to pass the stone from the intestine back into the gall-bladder. In the specimens that I have had the opportunity of dissecting, although

Fig. 8.

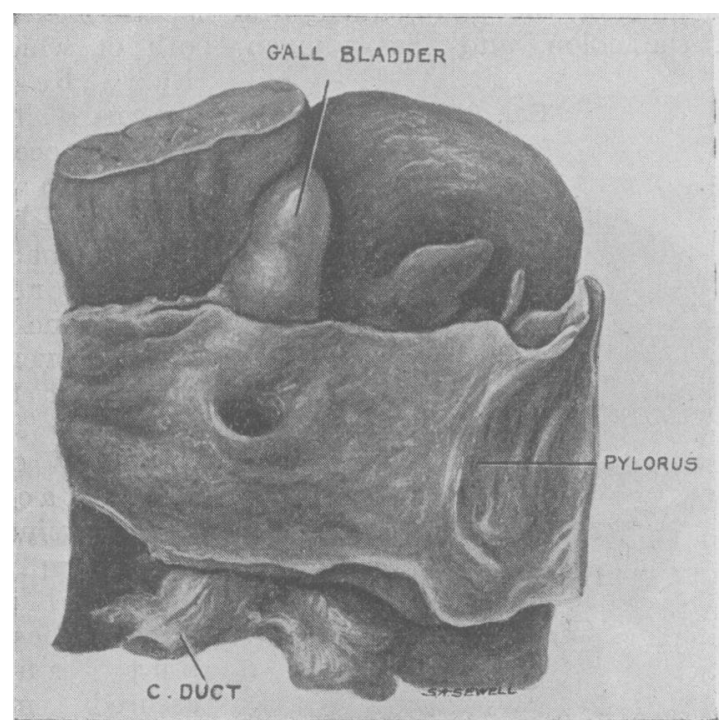

Fistula between the gall-bladder and duodenum through which a calculus was extruded into the bowel. The viscera are closely adherent and the fundus of the gall-bladder is thickwalled and flbrous from chronic inflammatory change. (From a specimen in the Museum of the University of Durham College of Medicine.)

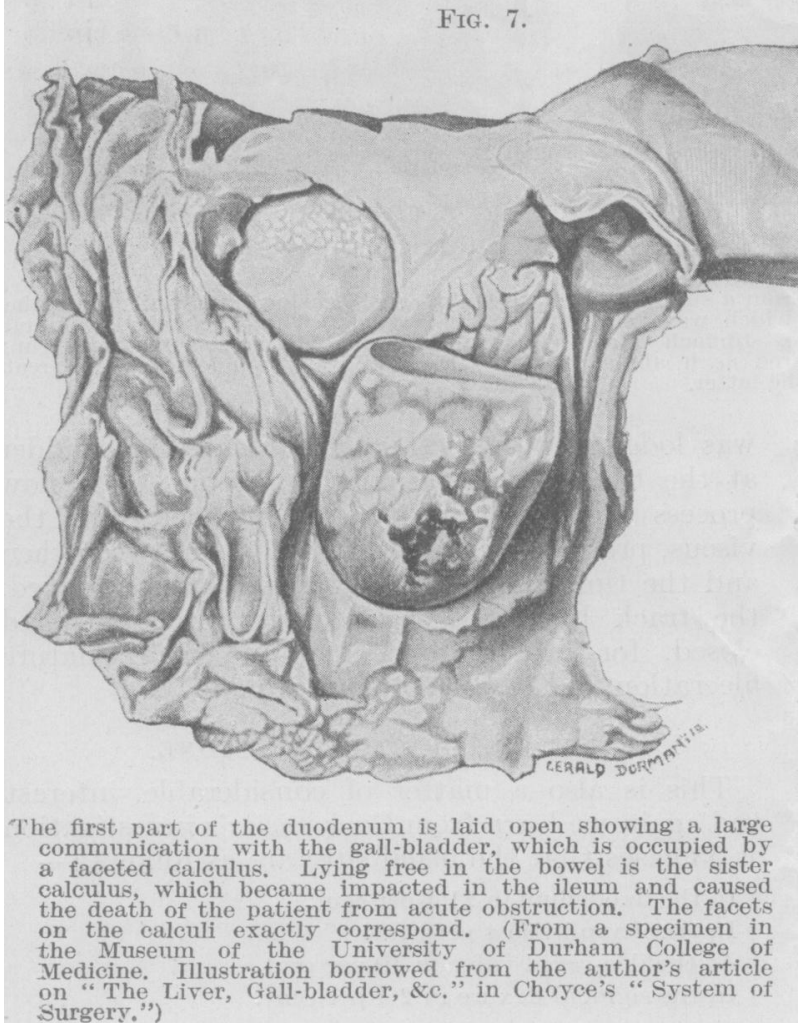

the stones were large $\left(17^{7 \prime} \times 1^{\prime \prime}\right.$ and $2 \frac{1}{4}^{\prime \prime} \times 1^{\prime \prime}$ respectively), the opening into the gall-bladder would only admit a forefinger and the margins were very rigid. The opening will surely contract down after the stone has passed, though a communication, however small, will always persist, forming the fistula bi-mucosa (Fig. 8). Many experiences have confirmed this view of what happens. All the stages of this process may be observed in the course of operations for gall-stones. Figs. 9 and $9 \mathrm{~A}$ represent the contents of gallbladders which I have removed. Any of these stones might have been the cause of intestinal obstruction had they found their way into the bowel. The calculus shown in Fig. 10 was removed from a suppurating gall-bladder in the case of a female patient 38 years of age. The inflamed viscus was very adherent to both the stomach and colon, and had there been no surgical intervention, it is highly probable that the large stone, which is just of the size to produce an intestinal obstruction, would have found its way by ulceration into the gastro-intestinal canal. Frequently when operating for gall-stones I have found communications between the viscus and some part of the bowel, and I have elsewhere drawn attention to the way that these tend to be drawn out and become infundibuliform, then presenting 
considerable danger, for they may be inadvertently treated as simple adhesions.

In July, 1909, I operated on a female patient aged 32 for the removal of a large ovarian cyst. A mass felt in the gall-bladder region was investigated, and a large stone found lying between the remains of the gall-bladder, the hepatic flexure of the colon, and the stomach, both of which
FIG. 9.

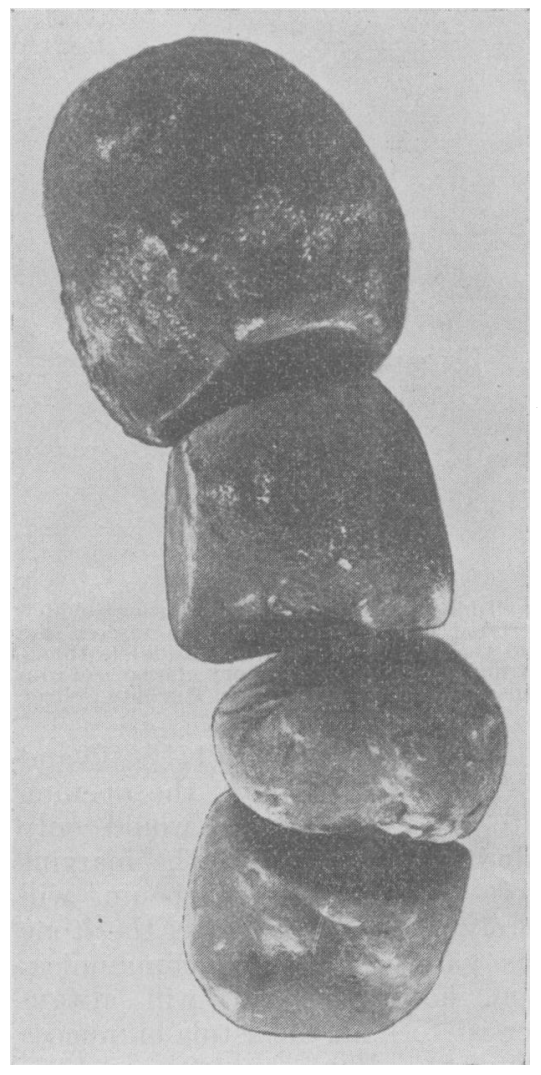

A group of large stones removed from the gall-bladder. Any one of these might have produced intestinal obstruction. had been opened by this process of slow ulceration. The patient made a good re covery, and I made every endeavour to obtain a history of an attack of abdominal pain or previous abdominal illness, b u t $\mathrm{s} \mathrm{h} \mathrm{e}$ assured me

FIG. 10.

health, and was able to resume employment in $\frac{\oplus}{6}$ bank. There was never the slightest suggestio of bladder trouble until April, 1925, when he bega to have frequent painful micturition. Thes Fig. 9A.

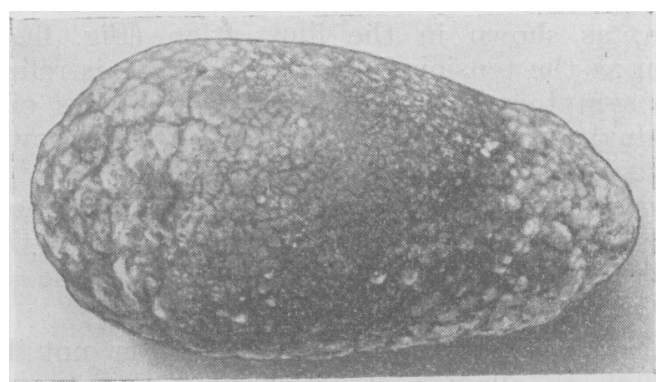

A large gall-stone removed from an inflamed gall-bladde It weighed $466 \mathrm{gr}$. and is just the sort that would probably cause intestinal obstruction.

symptoms continued until July, 1925, when ho was admitted under my care. Cystoscopic examination disclosed the piece of shell which I removeth (Fig. 11). There was only a slight cystitis, ang no scar to indicate where the fragment had enteref the bladder. There can be little doubt that

FIG. 11.

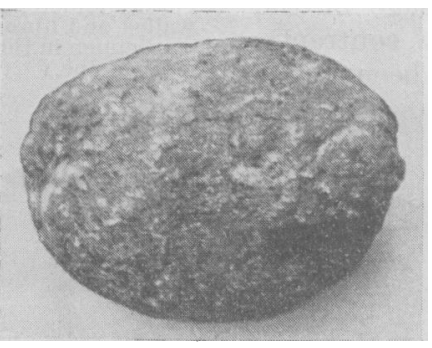

A gall-stone of the size likely to produce intestinal obstruction. It was removed from a suppurating gall-bladder which was very adherent to the stomach and colon and appeared as if about
to ulcerate into the latter.

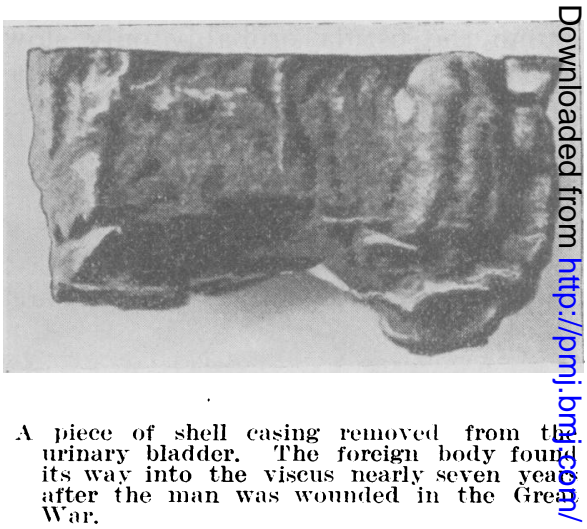
ivar that there had been none. This tendency of foreign bodies to find their way into the hollow viscera seems very general in pathology, and is certainly not limited to gall-stones. Some years ago I published (THE LANCET, May 6th, 1916) some cases of " Foreign Bodies in the Bladder resulting from Gunshot Wounds," and gave examples of foreign bodies which had slowly and gradually ulcerated into that viscus. Recently person of an ex-soldier who was wounded in May, 1917, portions of a shell being imbedded in the left buttock and thigh. Two operations were performed for removal of fragments, and later for secondary hæmorrhage. He eventually made a good recovery and was discharged from the Army in July, 1918. He soon regained his usual good I have had a further remarkable example in the at the time of the casualty, and that by a slo process of ulceration it was extruded into the viscus, probably about April, 1925. Between thei the track by which it entered the bladder had closed, for in the process employed by natu ulceration and repair go hand in hand.

Site of I MPaction of Stone.

This is also a matter of considerable interese and again we learn from Courvoisier's investigation of 53 cases that the usual sites are as follows :- 응

In the duodenum in 21.4 per cent.

In the ileum in 65.4 per cent.

At the ileo-creal valve in 10 per cent.

In the sigmoid flexure in 2.4 per cent. was lodged in the soft parts outside the bladd and the time that the foreign body was remove 
In all but one of my own cases the impaction took place in the small bowel.

There is evidence to show that sometimes even very large calculi may traverse the intestine, and I have notes of one case in which two calculi safely traversed the bowel until they.reached the anus, at which stage they became impacted.

The patient was a man of 61 , who was under my care over 20 years ago suffering from enlargement of the prostate. He told me that when 18 years of age he began to have attacks of pain attended by vomiting and followed by jaundice. During the next seven years he passed eight gall-stones ; six of these were only as big as small marbles, but two larger ones- $17_{\mathrm{S}}^{\prime \prime}$ and $2^{\prime \prime}$ in diameter-became impacted in the rectum and had to be removed by forceps. Since then he had never suffered from gall-stone pains.

\section{A SYMPOSIUM}

ON

\section{N D I G E S T I O N.}

Being Remarks of the Opening Speakers at a Recent Discussion on this subject at the Hunterian Society.

III. THE MEDICAL ASPECT.

BY

J. CAMPBELL McCLURE, M.D. GlasG., SENIOR PHYSICIAN TO THE FRENCH HOSIITAL, AND PHYSICIAN TO THE MARGARET-STREET HOSPITAL FOR CONSUMPTION, IONDON.

Fon the purposes of this discussion I would define indigestion as signs and symptoms, mostly referable to the abdomen, produced by a disorder of the normal action of the stomach and intestines.

One of the symptoms most commonly produced by disordered function of stomach and intestines is pain, which may vary from acute agony to a sensation of burning, or even mere discomfort. A feeling of distension with or without real swelling of the abdomen is another very common symptom, which may or may not be accompanied by the outward and visible signs of flatulence. Of the more common signs of indigestion, swelling of the abdomen, tenderness on pressure, muscular rigidity, flushing of the face, hot or cold hands and feet, are the most usual. These signs and symptoms may be associated with any lesion, functional or organic, of the whole alimentary tract, from the cardiac end of the stomach to the rectum, and it is often a matter of great difficulty to determine what part of the tract is at fault.

The main functions of the alimentary tract are dependent on its motility and powers of secretion. When pathologically disturbed, it may move too quickly or too slowly in part or in whole, and the secretion may be above or below the normal. These disorders may be the direct result of some gross local lesion of the mucous membrane in some part of the tract, or may be the result of faulty
The natural termination of cases in which the stones have caused obstruction is a matter of considerable interest. Though sometimes they safely pass and are voided per vias naturales with the complete cure of all symptoms, this fortunate happening is not the rule, and more commonly a stone once impacted either causes death by producing complete obstruction or by setting up peritonitis. As a rule the diagnosis has to be made from a consideration of the symptoms and by a process of exclusion. In a thin person the actual stone might be felt as a hard mass in the lower abdomen or bimanually and it might be detected by the $\mathrm{X}$ ray, although this is a method which is seldom employed in emergency cases.

( $T$ o be concluded.)

and ill:balanced innervation, or a fault in the secretion of the great accessory glands-the liver and the pancreas. It may be, however, secondary to a lesion arising entirely without the alimentary tract, whose activities may be impaired by the mechanical influence of, say, a tumour or an inflammatory process which has resulted in adhesions. So that when a person complains of pain in the epigastrium at some time or another after food, and nausea, vomiting, and constipation, both painstaking examination and reasoned interpretation of discovered facts are necessary for an accurate diagnosis.

\section{Pain as a Symptom of Innigestion.}

One of the most useful symptoms for study by the medical man is pain, and its careful location leads to very helpful diagnostic results. Pain in certain localities has proved to be at least very suggestive of lesions in definite parts of the alimentary canal. Even more helpful is the discovery of areas which are tender on palpation. A pyloric ulcer of the stomach is found to give rise to tenderness and rigidity in the middle line just below the xiphisternum. A duodenal ulcer very frequently gives rise to tenderness and rigidity in the right hypochondrium, pain being often referred as well to the right shoulder. The most common site of this hypochondriac pain is about midway between the middle line and the arch of the ribs, some two inches above the level of the ninth rib. Pain associated with a lesion of the gall-bladder is also felt in the right hypochondrium, with rigidity of the upper third of the right rectus muscle; the area of tenderness, however, found in connexion with this lesion is more definite and circumscribed, usually at a point on a level with the ninth rib and about two inches internal to its tip. Lesions of the jejunum and upper and middle ileum produce pain that is felt for the most part in the region of the umbilicus : lesions of the lower ileum as in typhoid fever produce pain in the right iliac fossa, and where there is rigidity, it is usually the middle third of the right rectus that is affected. The 